\title{
Analisis Tingkat Kepuasan Pasien Puskesmas Purnama Kecamatan Dumai Barat Kota Dumai
}

\author{
Fitra \\ Program Studi Teknik Industri Sekolah Tinggi Teknologi Dumai \\ Jl. Utama Karya Bukit Batrem II \\ E-mail: fie_fiet82@yahoo.co.id
}

\begin{abstract}
ABSTRAK
Puskesmas sebagai salah satu institusi kesehatan harus mampu memberikan pelayanan kesehatan yang bermutu bagi pasien. Kepuasan pada tiap diri pasien dapat dirasakan bila harapan dan kebutuhan pasien dapat terpenuhi, namun bila sebaliknya yang terjadi, maka pasien akan merasakan ketidakpuasan.Penelitian ini bertujuan untuk mengetahui apakah pasien puas terhadap pelayanan Puskesmas Purnama Kecamatan Dumai Barat kota Dumai. Metode Servqualdigunakan untuk menganalisa hasil penyebaran 100 kuesioner yang di isi oleh pasien Puskesmas Purnama dari 25 pertanyaan yang terkelompok dalam 5 dimensi yaitu: tangibles, reliability, responsiveness, assurance dan emphatybaik untuk kategori harapan maupun kenyataan pelayanan yang dirasakan oleh pasien.

Hasil uji validalitas dan reliabilitas untuk 25 variabel kenyataan dan harapan kuesioner servqualdinyatakan valid dan reliabel sedangkan dari hasil perhitungan nilai servqual untuk setiap dimensi antara kenyataan dan harapan yang di peroleh pasien terhadap kinerja pegawai Puskesmas Purnama untuk dimensi tangibles adalah 0,01 , dimensi reliability adalah 0,07 , dimensi responsiveness adalah 0,1 , dimensi assurance adalah 0,08 sedangkan dimensi emphaty adalah 0,12.

Berdasarkan nilai servqual disimpulkan bahwa kinerja pegawai Puskesmas Purnama memuaskan karena nilai servqual yang diperoleh $>0$ untuk setiap dimensi servqual dan harus dipertahankan.
\end{abstract}

Kata Kunci: Kepuasan, puskemas purnama, servqual.

\section{Pendahuluan}

Puskesmas merupakan salah satu fasilitas kesehatan yang sangat pentingbagi seluruh kalangan masyarakat, khususnya masyarakat ekonomi menengah kebawah. Faktor biaya periksa dan obat yang lebih murah, serta lokasinya yang mudah dijangkau (berada ditiap kelurahan) merupakan alasan utama masyarakat memilih puskesmas sebagai tempat pertama untuk berobat. Puskesmas sebagai institusi pemberi layanan kesehatan harus mampu memberikan kinerja yang bermutu dalam pelayanan kesehatan pelanggan. Dalam hal puskesmas pelanggan adalah pasien, sesuai dengan defenisi tentang pelanggan menurut Gasperz dalam Marpaung (2011). Pelanggan adalah orang yang tidak tergantung pada kita, tetapi kita yang tergantung padanya.Pelanggan adalah orang yang membawa kita ke keingnannya. 
Tjiptono dalam Marpaung, 2011 menyatakan bahwa bisnis bertujuan untuk menciptakan dan mempertahankan para pelanggan, begitu juga dengan puskesmas yang harus memberikan kinerja yang bermutu. Pelayanan yang bermutu merujuk pada kesempurnaan kinerja pegawai dalam memberikan pelayananan kesehatan yang akan menimbulkan kepuasan pada diri tiap pasien. Kepuasan diri tiap pasien dapat di rasakan bila harapan dan kebutuhan pasien terpenuhi, namum bila tidak sesuai dengan kebutuhan dan harapan pasien maka yang dirasakan pasien adalah ketidakpuasan.

Penelitian terdahulu yang dilakukan oleh Novaldi (2014) mengenai penentuan kualitas pelayanan terhadap kepuasan pasien RSUD Kota Dumaidengan 20 variabel dari 5 dimensi servqual yaitu: Tangibles, Realiability, Responsivness, Assurance dan Empaty. Hasil analisis 150 responden menunjukkan bahwa pasien merasa tidak puas terhadap pelayanan RSUD Dumai. Untuk meningkatkan kualitas layanan RSUD Dumai harus melakukan perbaikan disegala item dan RSUD Dumai harus konsisten dalam melakukan pelayanan pada pasien. Berbeda dengan penelitian sebelumnya yang melihat penentuan kualitas pelayanan terhadap kepuasan pasien RSUD Kota Dumai, pada penelitian ini akan melihat tingkat kepuasan yang diterima pasien Puskesmas Purnama dan mengetahui penyebab timbulnya ketidakpuasan pasien Puskesmas Purnama.

\section{Metode Penelitian}

Penelitian dilakukan di Puskesmas Purnama yang berada di Kecamatan Dumai Barat Kota Dumai dengan jumlah sampel penelitian adalah 100 pasien sedangkan langkah-langkah penelitian dapat dilihat pada Gambar 1.

Pendekatan kualitas pelayanan yang dijadikan acuan dalam penelitian ini adalah model Servqual (Service Quality) yang dikembangkan oleh Parasuraman, dkk (1990). Servqual dibangun atas adanya perbandingan dua faktor utama, yaitu persepsi pelanggan atas layanan nyata yang mereka terima dengan layanan yang sesungguhnya yang diharapkan/diinginkan.

Penelitian menggunakan metode servqual dan kuesioner sebagai instrumen penelitian yang terdiri dari 25 variabel pertanyaan untuk 5 dimensi servqual yaitu tangibles, reliability, responsiveness, assurance dan emphaty. Kuesioner yang dibuat menggunakan skala likert dimana angka 5 adalah sangat puas (SP), 4 adalah puas (P), 3 adalah cukup puas (CP), 2 adalah kurang puas (KP) dan angka 1 adalah tidak puas (TP). 


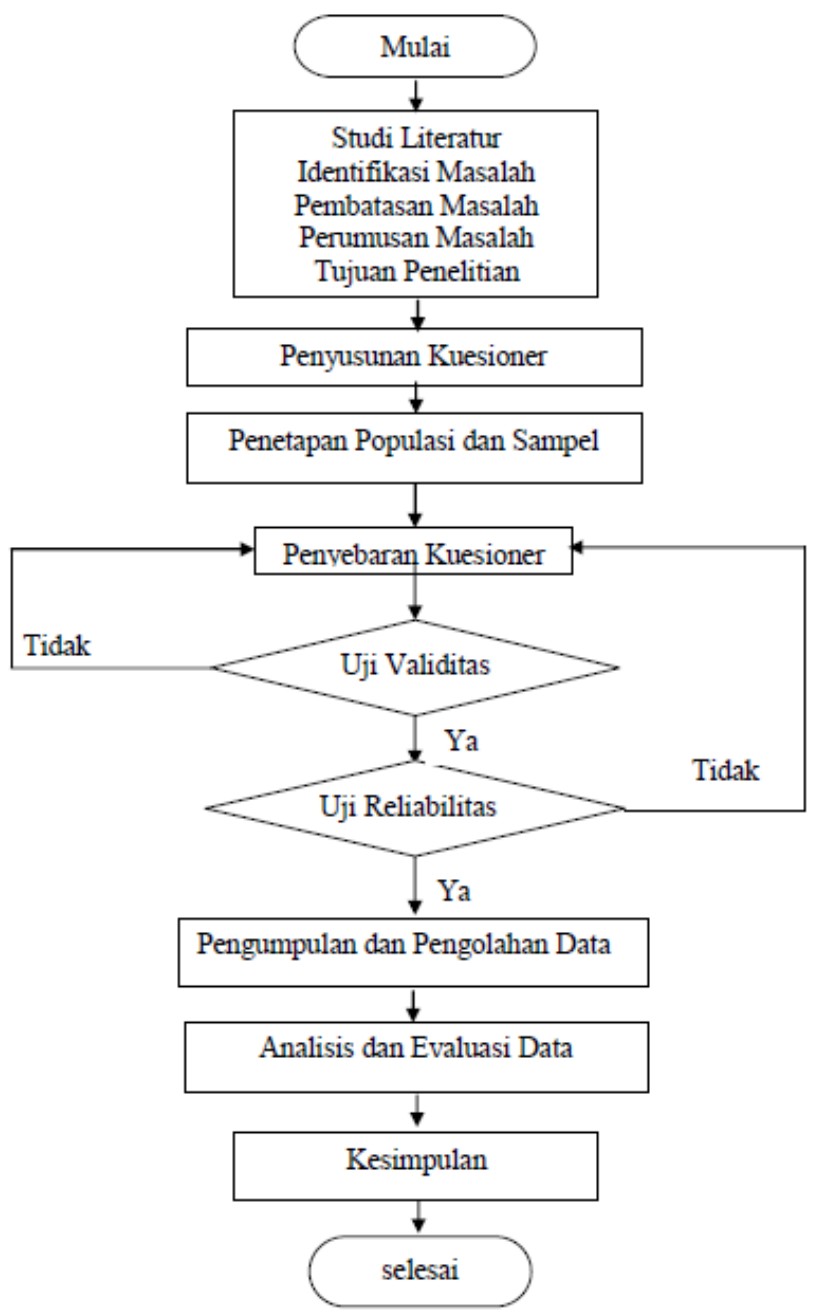

Gambar 1. Langkah-langkah penelitian

\section{Hasil dan Pembahasan}

\section{Uji Validitas dan Reliabilitas}

Setelah dilakukan penyebaran 100 kuesioner dan di isi oleh pasien Puskesmas Purnama dilakukan uji validitas untuk kategori kuesioner kenyataan dan harapan pasien dari 25 variabel yang dapat dilihat pada Tabel 1.

Tabel 1. Rekapitulasi hasil Uji Validitas kepuasan pasien di Puskesmas Purnama

\begin{tabular}{|l|l|l|l|l|l|l|}
\hline \multirow{2}{*}{$\begin{array}{c}\text { Variabel } \\
(\mathrm{X}, \mathrm{Y})\end{array}$} & \multicolumn{2}{|c|}{ Koefisien Korelasi } & \multicolumn{2}{c|}{ r hitung } & \multirow{2}{*}{ r Tabel } & \multirow{2}{*}{ Keterangan } \\
\cline { 2 - 5 } & Kenyataan & Harapan & Kenyataan & Harapan & & \\
\hline 1 & 0.284 & 0.376 & 0.335 & 0.458 & 0.197 & Valid \\
\hline 2 & 0.557 & 0.339 & 0.601 & 0.421 & 0.197 & Valid \\
\hline 3 & 0.351 & 0.347 & 0.400 & 0.421 & 0.197 & Valid \\
\hline 4 & 0.370 & 0.286 & 0.423 & 0.371 & 0.197 & Valid \\
\hline 5 & 0.439 & 0.240 & 0.489 & 0.328 & 0.197 & Valid \\
\hline 6 & 0.654 & 0.404 & 0.691 & 0.472 & 0.197 & Valid \\
\hline 7 & 0.632 & 0.449 & 0.677 & 0.525 & 0.197 & Valid \\
\hline
\end{tabular}




\begin{tabular}{|l|l|l|l|l|l|l|}
\hline \multirow{2}{*}{$\begin{array}{c}\text { Variabel } \\
(\mathrm{X}, \mathrm{Y})\end{array}$} & \multicolumn{2}{|c|}{ Koefisien Korelasi } & \multicolumn{2}{c|}{ r hitung } & \multirow{2}{*}{ r Tabel } & \multirow{2}{*}{ Keterangan } \\
\cline { 2 - 5 } & Kenyataan & Harapan & Kenyataan & Harapan & & \\
\hline 8 & 0.381 & 0.470 & 0.624 & 0.545 & 0.197 & Valid \\
\hline 9 & 0.518 & 0.347 & 0.577 & 0.436 & 0.197 & Valid \\
\hline 10 & 0.570 & 0.473 & 0.449 & 0.553 & 0.197 & Valid \\
\hline 11 & 0.612 & 0.379 & 0.656 & 0.463 & 0.197 & Valid \\
\hline 12 & 0.558 & 0.243 & 0.615 & 0.322 & 0.197 & Valid \\
\hline 13 & 0.474 & 0.400 & 0.525 & 0.480 & 0.197 & Valid \\
\hline 14 & 0.490 & 0.358 & 0.548 & 0.446 & 0.197 & Valid \\
\hline 15 & 0.520 & 0.322 & 0.569 & 0.412 & 0.197 & Valid \\
\hline 16 & 0.512 & 0.347 & 0.559 & 0.437 & 0.197 & Valid \\
\hline 17 & 0.521 & 0.392 & 0.560 & 0.455 & 0.197 & Valid \\
\hline 18 & 0.497 & 0.402 & 0.554 & 0.486 & 0.197 & Valid \\
\hline 19 & 0.574 & 0.360 & 0.629 & 0.436 & 0.197 & Valid \\
\hline 20 & 0.474 & 0.215 & 0.536 & 0.312 & 0.197 & Valid \\
\hline 21 & 0.526 & 0.334 & 0.669 & 0.411 & 0.197 & Valid \\
\hline 22 & 0.632 & 0.251 & 0.577 & 0.347 & 0.197 & Valid \\
\hline 23 & 0.609 & 0.215 & 0.653 & 0.284 & 0.197 & Valid \\
\hline 24 & 0.440 & 0.222 & 0.497 & 0.300 & 0.197 & Valid \\
\hline 25 & 0.597 & 0.375 & 0.639 & 0.451 & 0.197 & Valid \\
\hline
\end{tabular}

Tabel 1 menunjukkan bahwa dari 25 variabel kuesioner servqual untuk kenyataan dan harapan adalah valid dimana nilai $r$ hitung lebih besar dari nilai $r$ tabel untuk setiap variabel, sehingga pertanyaan tersebut dapat dijadikan sebagai alat ukur untuk mengetahui tingkat kepuasan pasien PuskesmasPurnama terhadap pelayanan yang diberikan. Setalah uji validitas dilakukan, maka langkah selanjutnya dilakukan uji reliabilitas yang hasilnya dapat dilihat pada Tabel 2.

Tabel 2. Rekapitulasi Uji Reliabilitas kepuasan pasien Puskesmas Purnama

\begin{tabular}{|l|l|l|l|}
\hline No & Koefisian Korelasi & Cronbach's Alpha & Keterangan \\
\hline 1 & Kenyataan & 0.910 & Reliabel \\
\hline 2 & Harapan & 0.809 & Reliabel \\
\hline
\end{tabular}

Tabel 2 merupakan hasil uji reliabilitas terhadap instrumen penelitian tingkat kepuasan pasien terhadap layanan puskesmas Purnama untuk kuesioner harapan dan kenyataan adalah reliabel karena nilai cronbach's alpha yang diperoleh di atas 0,6 menurut Sugiyono, 2004.

\section{MetodeServqual}

Setelah dilakukan uji validitas dan reliabilitas instrumen penelitian, maka langkah selanjutnya adalah melakukan perhitungan dengan menggunakan metode servqual, dimana yang dihitung adalah hasil jawaban pasien terhadap seluruh pertanyaan yang diberikan baik kenyataan maupun harapan. Hasil rekapitulasi nilai rata-rata kenyataan setiap variabel untuk Puskesman Purnama dapat dilihat pada Tabel 3 dan Tabel 4 untuk nilai rata-rata harapan pasien.

Tabel 3. Rekapitulasi nilai rata-rata kenyataan 


\begin{tabular}{|l|l|l|l|l|l|}
\hline No & Variabel & $\overline{X i}_{2}$ & \multicolumn{1}{|c|}{ No } & Variabel & $\overline{X i}_{2}$ \\
\hline 1 & $\mathrm{X}_{1}$ & 4.11 & 14 & $\mathrm{X}_{14}$ & 4.02 \\
\hline 2 & $\mathrm{X}_{2}$ & 4.09 & 15 & $\mathrm{X}_{15}$ & 4.11 \\
\hline 3 & $\mathrm{X}_{3}$ & 4.05 & 16 & $\mathrm{X}_{16}$ & 3.85 \\
\hline 4 & $\mathrm{X}_{4}$ & 3.99 & 17 & $\mathrm{X}_{17}$ & 4.02 \\
\hline 5 & $\mathrm{X}_{5}$ & 4.05 & 18 & $\mathrm{X}_{18}$ & 3.99 \\
\hline 6 & $\mathrm{X}_{6}$ & 3.86 & 19 & $\mathrm{X}_{19}$ & 4.24 \\
\hline 7 & $\mathrm{X}_{7}$ & 3.85 & 20 & $\mathrm{X}_{20}$ & 4.06 \\
\hline 8 & $\mathrm{X}_{8}$ & 4.02 & 21 & $\mathrm{X}_{21}$ & 3.96 \\
\hline 9 & $\mathrm{X}_{9}$ & 4.13 & 22 & $\mathrm{X}_{22}$ & 3.96 \\
\hline 10 & $\mathrm{X}_{10}$ & 4.21 & 23 & $\mathrm{X}_{23}$ & 4.00 \\
\hline 11 & $\mathrm{X}_{11}$ & 4.00 & 24 & $\mathrm{X}_{24}$ & 4.13 \\
\hline 12 & $\mathrm{X}_{12}$ & 4.09 & 25 & $\mathrm{X}_{25}$ & 4.11 \\
\hline 13 & $\mathrm{X}_{13}$ & 3.90 & & & \\
\hline
\end{tabular}

Tabel 4. Rekapitulasi nilai rata-rata Harapan

\begin{tabular}{|l|l|l|l|l|l|}
\hline No & Variabel & \multicolumn{1}{|c|}{$\overline{Y i}_{2}$} & No & Variabel & $\overline{Y i}_{2}$ \\
\hline 1 & $\mathrm{Y}_{1}$ & 4.09 & 14 & $\mathrm{Y}_{14}$ & 4.04 \\
\hline 2 & $\mathrm{Y}_{2}$ & 4.16 & 15 & $\mathrm{Y}_{15}$ & 4.19 \\
\hline 3 & $\mathrm{Y}_{3}$ & 3.89 & 16 & $\mathrm{Y}_{16}$ & 3.99 \\
\hline 4 & $\mathrm{Y}_{4}$ & 4.01 & 17 & $\mathrm{Y}_{17}$ & 4.01 \\
\hline 5 & $\mathrm{Y}_{5}$ & 4.08 & 18 & $\mathrm{Y}_{18}$ & 3.96 \\
\hline 6 & $\mathrm{Y}_{6}$ & 3.68 & 19 & $\mathrm{Y}_{19}$ & 3.83 \\
\hline 7 & $\mathrm{Y}_{7}$ & 3.77 & 20 & $\mathrm{Y}_{20}$ & 4.04 \\
\hline 8 & $\mathrm{Y}_{8}$ & 3.66 & 21 & $\mathrm{Y}_{21}$ & 3.81 \\
\hline 9 & $\mathrm{Y}_{9}$ & 4.25 & 22 & $\mathrm{Y}_{22}$ & 3.79 \\
\hline 10 & $\mathrm{Y}_{10}$ & 4.32 & 23 & $\mathrm{Y}_{23}$ & 3.98 \\
\hline 11 & $\mathrm{Y}_{11}$ & 3.77 & 24 & $\mathrm{Y}_{24}$ & 3.96 \\
\hline 12 & $\mathrm{Y}_{12}$ & 3.92 & 25 & $\mathrm{Y}_{25}$ & 4.03 \\
\hline 13 & $\mathrm{Y}_{13}$ & 3.72 & & & \\
\hline
\end{tabular}

Setelah diperoleh nilai rata-rata kenyataan yang dirasakan oleh pasien dan harapan yang diinginkan oleh pasien, maka langkah selanjutnya menghitung nilai servqual berdasarkan GAP dari 5 dimensi yang dapat dilihat pada Tabel 5 .

Tabel 5.Rekapitulasi hasil nilai gap

\begin{tabular}{|l|l|l|l|l|l|l|l|}
\hline $\begin{array}{l}\text { Variabel } \\
(\mathrm{X}, \mathrm{Y})\end{array}$ & $\overline{X i}_{2}$ & $\overline{Y i}_{2}$ & $\mathrm{SQi}$ & $\begin{array}{l}\text { Variabel } \\
(\mathrm{X}, \mathrm{Y})\end{array}$ & $\overline{X i}_{2}$ & $\overline{Y i}_{2}$ & $\mathrm{SQi}_{2}$ \\
\hline 1 & 4.11 & 4.09 & 0.02 & 14 & 4.02 & 4.04 & -0.02 \\
\hline 2 & 4.09 & 4.16 & -0.07 & 15 & 4.11 & 4.19 & -0.08 \\
\hline 3 & 4.05 & 3.89 & 0.16 & 16 & 3.85 & 3.99 & -0.14 \\
\hline 4 & 3.99 & 4.01 & -0.02 & 17 & 4.02 & 4.01 & 0.01 \\
\hline
\end{tabular}




\begin{tabular}{|l|l|l|l|l|l|l|l|}
\hline $\begin{array}{l}\text { Variabel } \\
(\mathrm{X}, \mathrm{Y})\end{array}$ & $\overline{\mathrm{Xi}}_{2}$ & $\overline{\mathrm{Yi}}_{2}$ & $\mathrm{SQi} 2$ & $\begin{array}{l}\text { Variabel } \\
(\mathrm{X}, \mathrm{Y})\end{array}$ & $\overline{\mathrm{Xi}}_{2}$ & $\overline{\mathrm{Yi}}_{2}$ & $\mathrm{SQi}_{2}$ \\
\hline 5 & 4.05 & 4.08 & -0.03 & 18 & 3.99 & 3.96 & 0.03 \\
\hline 6 & 3.86 & 3.68 & 0.18 & 19 & 4.24 & 3.83 & 0.41 \\
\hline 7 & 3.85 & 3.77 & 0.08 & 20 & 4.06 & 4.04 & 0.02 \\
\hline 8 & 4.02 & 3.66 & 0.36 & 21 & 3.96 & 3.81 & 0.15 \\
\hline 9 & 4.13 & 4.25 & -0.12 & 22 & 3.96 & 3.79 & 0.17 \\
\hline 10 & 4.21 & 4.32 & -0.11 & 23 & 4.00 & 3.98 & 0.02 \\
\hline 11 & 4.00 & 3.77 & 0.23 & 24 & 4.13 & 3.96 & 0.17 \\
\hline 12 & 4.09 & 3.92 & 0.17 & 25 & 4.11 & 4.03 & 0.08 \\
\hline 13 & 3.90 & 3.72 & 0.18 & & & & \\
\hline
\end{tabular}

Sedangkan untuk pengukuran nilai servqual diperoleh berdasarkan hasil pengurangan nilai skor kenyataan dikurangi skor harapan yang dapat dilihat pada Tabel 6.

Tabel 6. Rekapitulasi nilai Servqual setiap dimensi Puskesmas Purnama

\begin{tabular}{|l|l|l|l|l|}
\hline No & Dimensi Servqual & Skor Kenyataan & Skor Harapan & Nilai Servqual \\
\hline 1 & Tangibles & 4.06 & 4.05 & 0.01 \\
\hline 2 & Reliability & 4.01 & 3.94 & 0.07 \\
\hline 3 & Responsiveness & 4.02 & 3.92 & 0.10 \\
\hline 4 & Assurance & 4.03 & 3.95 & 0.08 \\
\hline 5 & Emphaty & 4.03 & 3.91 & 0.12 \\
\hline
\end{tabular}

Dari hasil perhitungan Tabel 6dapat dianalisis nilai servqual untuk setiap dimensi antara kenyataan dan harapan yang di peroleh pasien terhadap kinerja pegawai Puskesmas Purnama dengan milihat nilai servqual yang diperoleh. Jika nilai yang didapat $>0$ maka dinyatakan memuaskan. Demikian juga sebaliknya apabila nilai yang didapat $<0$ maka dinyatakan tidak memuaskan sehingga:

1. Dimensi Tangibles (Keadaan Fisik)

Berdasarkan nilai servqual yang didapat yaitu 0.01 dinyatakan bahwa pasien puas dengan kinerja pagawai Puskesmas Purnama yang diberikan baik dalam bentuk kebersihan lingkungan, penampilan pegawai, kondisi fisik layanan, kelengkapan dan kesiapan alat-alat, penataan interior dan eksterior.

2. Dimensi Reliability (Kehandalan)

Nilai servqual 0.07 menunjukkan bahwa pasien merasa puas dengan kinerja pegawai Puskesmas Purnama baik dalam bentuk prosedur, tindakan cepat, kesiagaan dalam pelayanan, pengadministrasi dan pegawai registrasi di tempat.

3. Dimensi Responsiveness (Daya Tanggap)

Sedangkan nilai servqual 0.1 menunjukkan bahwa pasien juga puas dengan kinerja pegawai Puskesmas Purnama baik dalam bentuk kesiagaan pegawai, reaksi cepat dan tanggap terhadap keluhan, pemberian informasi yang jelas, tidak menunggu lama dalam pelayanan, tidak perlu waktu lama mendaftar

4. Dimensi Assurance (Jaminan)

Nilai servqual 0.08 menujukkan bahwa pasien merasa puas dengan kinerja Puskesmas Purnama. 
5. Dimensi Empathy (Empati)

Sedangkan nilai servqual 0.12 menunjukkan bahwa pasien juga puas denngan kinerja pegawai Puskesmas Purnama yang diberikan baik dalam bentuk perhatian khusus, peduli terhdap kebutuhan dan keinginan pasien, pemberian pelayanan tanpa padang status sosial, kesediaan dalam menangani keluhan, kesediaan dalam pemberian informasi.

\section{Simpulan}

Dari hasil penelitian yang diperoleh, maka dapat disimpulkan bahwa pasien Puskesmas Purnama sudah Puas terhadap pelayanan atau kinerja yang diberikan dan harus dipertahankan.

\section{Daftar Pustaka}

Agusno H., 2014, Pengaruh kualitas jasa pengkreditan terhadap loyalitas konsumen pada PT. BFI Finance. Tbk Dumai. Sekolah Tinggi Teknologi Dumai.

Hasan, M.I., 2001, Pokok-pokok materi Statistik 2, (Statistik Inferensif) Edisi 2, Bina Aksara, Jakarta.

Hidayat R., 2012, Penentuan Faktor-Faktor Yang Mempengaruhi Kinerja Pegawai pada PT. METITO Indonesia. Sekolah Tinggi Teknologi Dumai.

Jonathan S., 2012, IBM SPSS, Advanced Statistic, ANDI, Yogyakarta.

Nofrialdi, 2014., Kualitas Pelayanan Terhadap Kepuasan Pasien RSUD Kota Dumai, Tugas Akhir Sekolah Tinggi Teknologi Dumai.

Santoso, S., 2008., Panduan Lengkap Menguasai SPSS 16, Alex Media Komputindo, Kelompok Gramedia, Jakarta

Susanto M.,dan Adi Y.N., 2012, Pengaruh Pelatihan Dan Motivasi Kerja Terhadap Kinerja Karyawan PT. ISS Indonesia. Sekolah Tinggi Teknologi Dumai.

Sekolah Tinggi Teknologi Dumai, 2015., Panduan Penyusunan Penulisan Laporan Kerja Praktek dan Tugas Akhir, edisi ke V Dumai.

Tjiptono, F.,dan Chandra, G., 2005, Service, Quality \& Satisfaction, edisi: 3 Yogyakarta.

Widoyoko, E., dan Putro,2013, Teknik Penyusunan Instrumen Penelitian Pustaka Pelajar, Yogyakarta. 